\title{
The French-Italian Concordia Station
}

\author{
Djamel Mekarnia ${ }^{1}$ and Yves Frenot ${ }^{2}$ \\ ${ }^{1}$ Université de Nice, Observatoire de la Côte d'Azur, CNRS UMR 7293, \\ Bd de l'Observatoire, BP 4229, F-06304 Nice Cedex 4, France \\ email:mekarnia@oca.eu \\ ${ }^{2}$ IPEV - Institut polaire français Paul Emile Victor, Technopôle Brest-Iroise, \\ BP 75, F-29280 Plouzané, France \\ email: y.frenot@ipev.fr
}

\begin{abstract}
Concordia is a French-Italian permanent station located at Dome C, Antarctica. The station provides accommodation for up to 16 people over winter and more than 70 scientists and technicians during the austral summer. The scientific projects implemented at Concordia are strictly dependent on the characteristics of the site: a) the presence of a $3300 \mathrm{~m}$ thick ice cap that allows access to the planet's climate archives and the reconstruction of glacial-interglacial cycles over more than 800000 years; b) a particularly stable pure and dry atmosphere ideal for astronomy observations and for research on the chemical composition of the atmosphere; $c$ ) a distant location from coastal perturbations favourable to magnetic and seismological observatories to complement a poor world data network in the southern hemisphere; and d) a small totally isolated group of people confined to the station over a long winter, offering an opportunity for a range of medical and psychological studies useful to prepare long duration deep space missions.

We will address the main characteristics of this station and its interest for science.
\end{abstract}

\section{Introduction}

The East Antarctic plateau at Dome $\mathrm{C}$ is one of the coldest and among the most remote places on Earth. Dome C is $1100 \mathrm{~km}$ from the coast at a height of $3233 \mathrm{~m}$ above sea, surrounded by thousands of kilometers of solid ice. Temperatures hardly rise above $-25^{\circ} \mathrm{C}$ in summer and can fall below $-80^{\circ} \mathrm{C}$ in winter with record of $-84.6^{\circ} \mathrm{C}$ reached in 2010 . Dome $\mathrm{C}$, one of the high points of the Plateau, was originally selected for glaciological reasons as one of the two sites of the EPICA deep ice-core drilling project that reached solid ground at a depth of $3270 \mathrm{~m}$ in December 2004. Ten countries were associated in this program which provided a climate reconstruction of about 800000 years. These results were at the basis of the IPCC (Intergovernmental Panel on Climate Change) discussions during the last years and provided evidence of the responsibility of Humans in the recent increase in the $\mathrm{CO}_{2}$ or methane concentration in the atmosphere.

Concordia is jointly funded, staffed and operated by the French polar institute, IPEV and the Italian national program, PNRA, through the Italian national agency, ENEA, under a cooperative agreement signed by IPEV and PNRA in 1993. IPEV is a French governmental support agency for the scientific researches in the northern and southern polar regions, including the sub-antarctic islands (Crozet, Kerguelen and Amsterdam), with a staff of 50 permanent and up to 200 contract employees. The main IPEV partners are the French Ministry of Research and the CNRS (French National Centre for Scientific Research). ENEA is the Italian national agency for new technologies, energy and sustainable economic development.

Concordia opened in 1997 with the establishment of a summer camp. The year round facility station was built in five summer seasons, and Concordia became the third permanent continental station in February 2005, besides Vostok (Russia) and Amundsen-Scott 


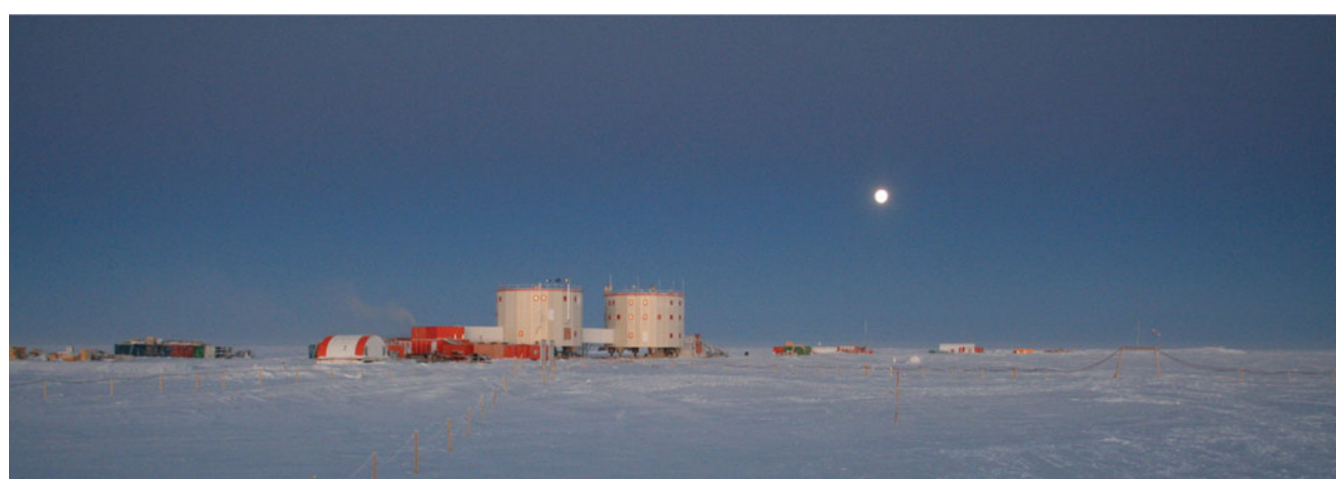

Figure 1. Main buildings of the Concordia station.

(USA) stations. As one of the newest stations in Antarctica, Concordia uses an efficient energy and waste management systems.

With mostly katabatic winds of less than $20 \mathrm{~m} / \mathrm{s}$, almost no absolute humidity, no light or air pollution, very low atmospheric turbulence and an inversion layer reaching up to just $30 \mathrm{~m}$ above ground, Dome C, which was selected for glaciology, is shifting it interests to atmospheric sciences and astronomy and astrophysics. The station hosts a large number of international scientific programs with participation of the researchers from mostly European countries.

\section{The Station}

Concordia station consists of two main identical polygonal buildings which are interlinked by enclosed walkways (Fig. 1). The two large three-storeyed buildings which provide the station's main living and working quarters, are divided for quiet and loud activities, respectively. The calm building houses laboratories, lodging, communications, and medical facilities, while the noisy building houses the kitchen, the dining area, the gym, a video room, and some storage and technical plants. Each housing unit is $18.5 \mathrm{~m}$ in diameter and has $250 \mathrm{sqm}$. A third structure, made up of stacked and interlocked containers, houses power station and mechanical facilities.

During the summer, up to 34 people can be housed in the main station buildings, while the overflow (up to 50) population can be housed in the summer camp. During the winter, only the main buildings are opened (the summer camp becoming an emergency camp) and capable of providing home to up to 16 people winter over crew.

The station, which has a fully equipped medical facility, including an operating room and a dental suite, provides an absolute comfort in a place where external temperature can drop as low as $-84^{\circ} \mathrm{C}$.

\section{Logistics}

Access to Concordia station is limited to the austral summer due to the extreme weather conditions. For more than nine months per year, the station functions fully autonomously and has access to the outside world only through communication systems. There are two different ways to access the station. Coming from Hobart, Australia, by ship (L'Astrolabe) to the French coastal station Dumont d'Urville, or from Christchurch (New-Zealand) by intercontinental plane (Hercules aircraft) to the Italian station Mario- 
Zucchelli at Terra-Nova bay. For transportation of people, Twin Otter or Basler aircrafts are used, starting from either Dumont d'Urville or Mario Zucchelli stations.

L'Astrolabe's cargo is transferred from Dumont d'Urville, which is located on an island, to Cap Prud'homme station, a small annex station on the continent, $5 \mathrm{~km}$ far from Dumont d'Urville, by helicopter, by pontoon or by sledges, depending on the sea-ice and weather conditions.

Selected light cargo is transported to Concordia by plane while heavy equipment is brought to Concordia using ground traverses. Cap Prud'homme serves as the continental launching point for these inland traverses. A typical traverse convoy consists of two or three snow grading machines leading eight to ten tractors towing the cargo sledges, and covering $1200 \mathrm{~km}$ in 8-10 days depending on weather conditions. Approximately 150 tons of cargo is brought on each traverse, two thirds of which is fuel. IPEV is the leader in the development and implementation of such inland traverses in Antarctica. Even if less rapid than aircraft, this concept has many advantages: it is cheaper, it is not weatherdependent (geolocation system is needed to allow navigation in bad weather conditions), it requests less maintenance, and is safer for the environment.

\section{Power station}

The power station is made up of 3 Diesel generators, adapted to the particular conditions of the air in Dome C. Each generator can deliver at least $125 \mathrm{~kW}$ at full load. The system is a co-generator one that lets the recovering of waste heat for a total amount of around $80 \%$. The waste heat is used to heat the station year round without additional heaters.

Concordia station was designed for power production and fuel consumption efficiency. Maximum consumption in the summer season averages $150 \mathrm{~kW}$. Concordia's fuel as well as kerosene, petrol and other fuels for vehicles arrives by tractor traverse and is stored in tanks inside specially constructed containers. A spatially removed supply of fuel is present at the summer/emergency camp.

For safety reasons, there is also an emergency Diesel generator inside the noisy building.

\section{Telecommunications}

Dome $\mathrm{C}$ is still in the line of sight of existing geostationary satellites, then Concordia station has a permanent VSAT $512 \mathrm{kbps}$ connection using a $3.8 \mathrm{~m}$ antenna. The satellite connection is used mainly for text emails and small data volume transfer. The station has also Iridium and Inmarsat satellite systems allowing a bandwidth of $64 \mathrm{kbps}$, a VoIp conferencing room and medical teleconference capabilities.

All around the station up to about $1 \mathrm{~km}$, scientific instruments and warmed shelters are connected by fiber optics to a switch located into the main buildings, where the network runs at $1 \mathrm{Gbps}$.

\section{Water-recycling}

Fresh water is obtained by melting snow collected from a designated clean area. To protect the Antarctic environment, waste water is appropriately treated. It is separated into two different units: the grey and the black water units. The grey water treatment unit (GWTU) was designed together with the European Space Agency (ESA). It converts waste water to potable water which is used only for personal hygiene applications, even if it can be safely consumed. A four-step treatment process including ultrafiltration, nano 
filtration and two stages of reverse osmosis is realized. Treated water from the black water system is taken up by the grey water treatment unit and recycled. Solid waste from the black water system is containerized and removed from the continent as hazardous waste.

\section{Scientific activities}

The objective of Concordia is to operate, year-round, as an international research facility. Beside the glaciology programs, the remote inland location of the station provides an excellent site for astronomy and astrophysics, geophysics (seismology and geomagnetism), atmospheric sciences and human biology and medicine.

Concordia's science facilities are located in area surrounding the main station up to one kilometer away (Fig. 2). During summer, experiments can be performed up to a few kilometers (5 to 20) from the main station. If necessary, summer science traverses can be organized to perform scientific studies (glaciology, seismology, ...) up to Vostok station located at $560 \mathrm{~km}$ from Concordia.

The main scientific activities conducted at Concordia are the following :

- Beside, the EPICA ice-core, which was completed in December 2004, reaching a depth of $3270.2 \mathrm{~m}, 5 \mathrm{~m}$ above bedrock, and extended the record of climate variability to an age estimated to be around 800000 years old, Concordia remains an active site for glaciology with a large number of scientific experiments conducted on this field year round.

- During winter-over, Concordia station shares many stressor characteristics with long duration deep space missions, particularly extreme isolation and confinement. For this reason, ESA is interested in Concordia as a model of space vessel, simulating a human mission to Mars by the year 2030. The space agency accordingly supports several experiments in the field of space medicine and psychology, involving volunteers from the winter crew.

During the winter, the crew are without possibility of evacuation or deliveries for 9 months and live for a period of 3 months in total darkness, at altitude almost equivalent to $4000 \mathrm{~m}$ at the equator. Experiments conducted at Concordia during winter-over are

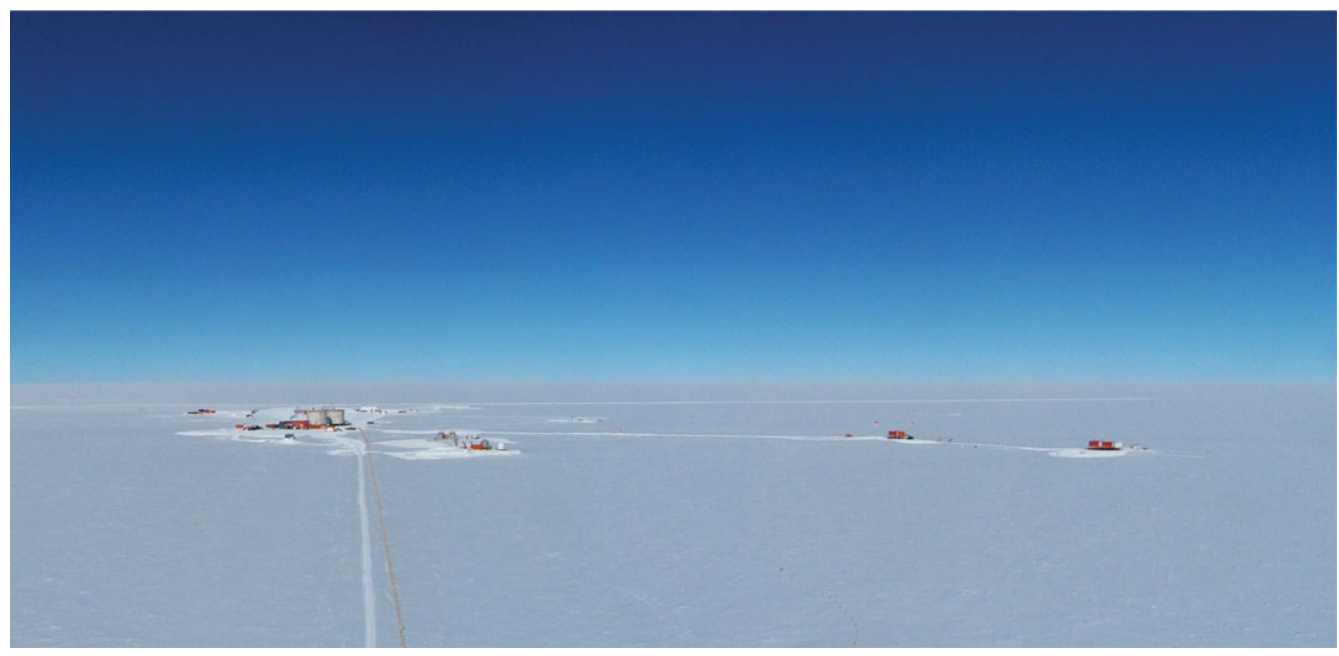

Figure 2. Panoramic view of Concordia station showing the main scientific installations. 
linked to the physiological and psychological strains on the crew, particularly for the study of chronic hypobaric hypoxia, the stress secondary to confinement and isolation, the circadian rhythm and sleep disruption and the individual and group psychology.

- Concordia station is an opportunity for long term observatories in meteorology, seismology and earth magnetism, to supplement the worldwide Earth observatories network in a region where its coverage remains very sparse.

Since 1998, Concordia has housed a permanent seismological observatory. The seismology station was constructed progressively over six summer campaigns, at the same time as the scientific base itself. The seismology program at Concordia has two main goals: the set-up and operation of a broad-band "observatory-quality" permanent seismic station, and the deployment of a temporary seismometer array. Both aspects of the program aim to contribute to the study of both Earth structure and earthquakes.

- Concordia permanent magnetic observatory was opened at the beginning of 2005 . The observatory is equipped with standard instruments for continuous three-component field variation records and absolute measurements. The observatory, located above more than $3000 \mathrm{~m}$ of layered ice, is unaffected by crustal field contaminations and coastal tidal effects. Furthermore, it lays inside the Southern polar cup, close to the South corrected geomagnetic pole. In these regions, the Earth's magnetic field is stronger and the external field influences are enhanced.

- Several programs are implemented in the field of atmospheric sciences, including air/snow interactions, as well as in the specific domain of ozone dynamics. Among them, the Concordiasi project, a French-US initiative for climate/meteorology over Antarctica at a global scale is a good example of a large international study (Hertzog et al. 2010) (Fig. 3). Many agencies or scientific organizations were involved: Météo-France, CNES, CNRS/INSU, NSF, NCAR, University of Wyoming, Purdue University, University of Colorado, the Alfred Wegener Institute, the Met Office and ECMWF. Concordiasi has benefited from logistic or financial support of the operational polar agencies IPEV, PNRA, USAP and BAS, and from BSRN (Baseline Surface Radiation Network) mea-

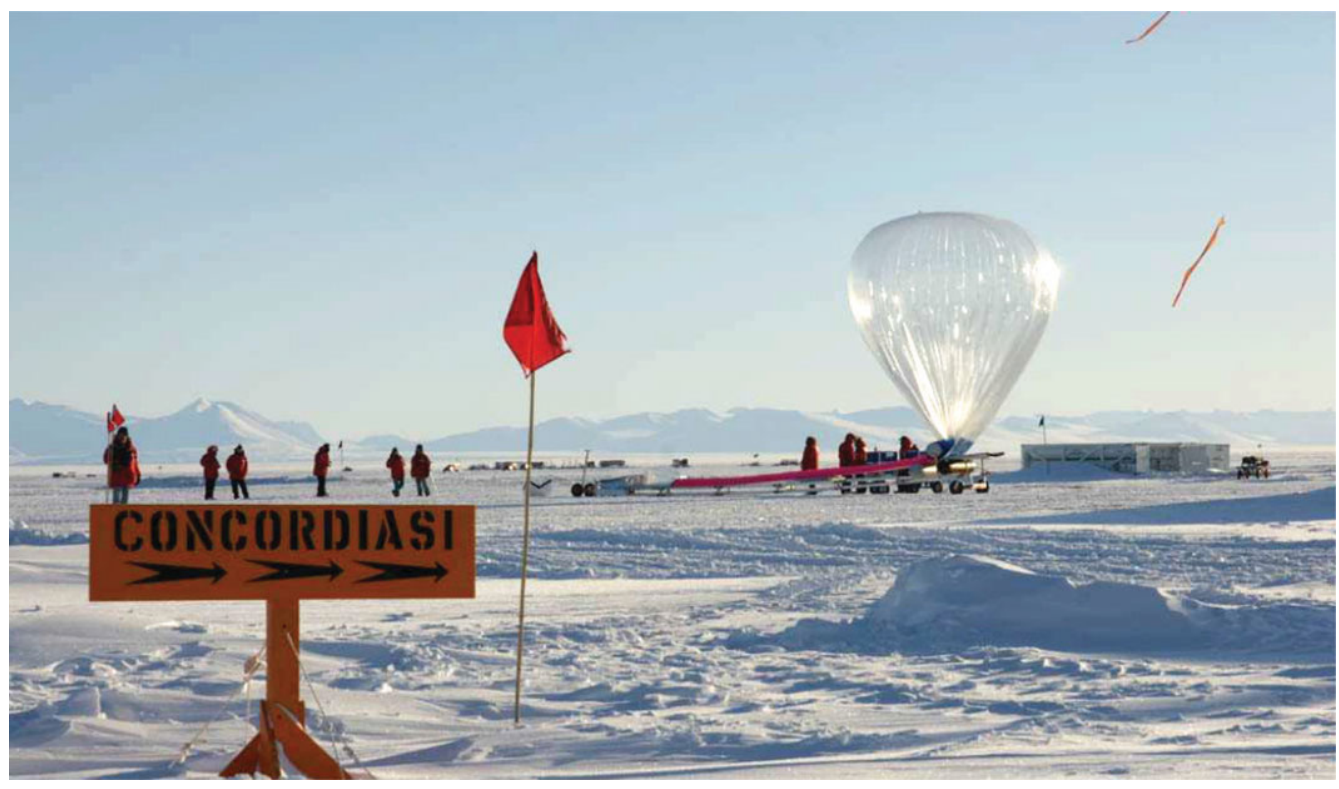

Figure 3. Concordiasi: Launch preparation from McMurdo station (CNES Image). 
surements at Concordia. Concordiasi was part of the THORPEX-IPY cluster within the International Polar Year effort.

Three field experiments were conducted, two which have occurred during the austral autumn 2008 and austral spring 2009 in Antarctica and a third one in austral spring 2010. In September and October 2009, 18 drifting balloons were released to acquire measurements in the stratosphere. Twelve of them released 600 parachuted dropsondes to establish vertical profiles of the troposphere. Additional in-situ measurements include radio-soundings at the Concordia station and at Dumont d'Urville, and high altitude balloons able to drop dropsondes, were launched on demand under a parachute to measure atmospheric parameters on their way down over Antarctica in 2010. Some of the balloons carried experimental instruments measuring ozone and particles at flight level. Others, also, have been improved for carrying GPS receivers to perform radio-occultation measurements.

\section{Astronomy and Astrophysics}

Concordia station had received world-wide attention from the astronomical community when it became known that the seeing conditions on Dome $\mathrm{C}$ are likely the best on the entire planet at a height of approximately $30 \mathrm{~m}$ above ice surface (Lawrence et al. 2004, Agabi et al. 2006, Aristidi et al. 2003, 2005a, 2005b). Extensive site quantification were conducted since the first winter-over in 2005, confirming an excellent seeing above a thin boundary layer (Aristidi et al. 2009, Fossat et al. 2010), a very low scintillation (Kenyon et al. 2006) a low sky brightness (Kenyon \& Storey 2006) and a high duty cycle (Mosser \& Aristidi 2007, Crouzet et al. 2010). In addition, as expected by Dempsey et al. (2005), photometric observations conducted at Concordia are not affected by Aurorae.

Thanks to the cold, dry, and calm atmosphere, Concordia offers the best conditions on Earth to investigate astronomical objects at high angular resolution, particularly in

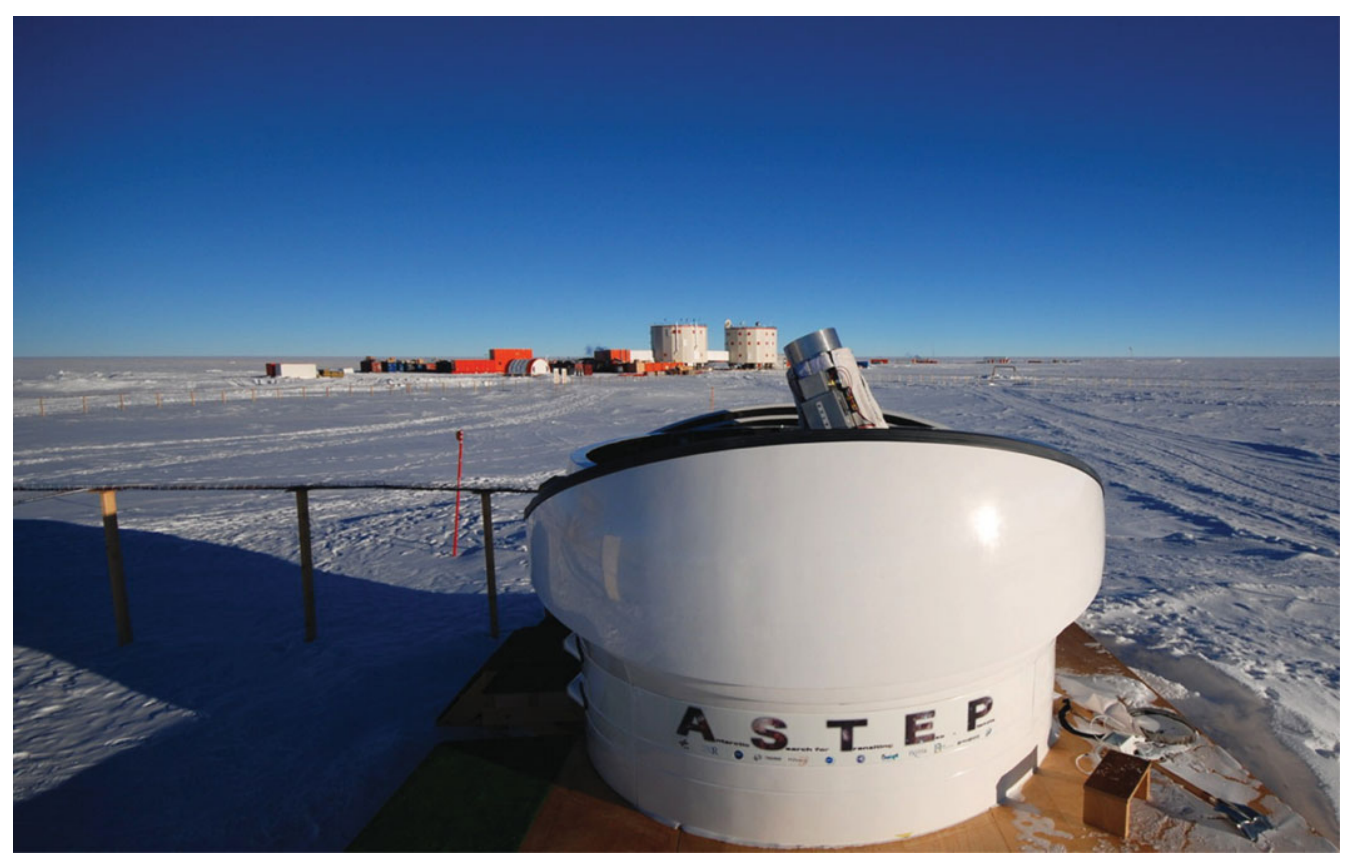

Figure 4. ASTEP 400 telescope at Concordia. 
the near thermal IR and submillimeter-wave ranges. The high latitude location allows 3-month continuous night-time photometric observations, which makes it an ideal site for long-duration observations such as those required to study the periodic variability of celestial objects and to detect and characterize exoplanets. In several well-identified domains (niches), the Antarctic plateau may even compete with space missions, but at a much lower cost, and with the invaluable bonus of using the most advanced technologies.

The main astronomy experiments conducted at Concordia are the following :

- IRAIT - the International Robotic Antarctic Infrared Telescope - is a Cassegrain $80 \mathrm{~cm}$ telescope having an alt-azimuth mount and two stable Nasmyth focal stations (Tosti et al. 2006). The telescope was installed at Concordia in 2008. It is provided with a wobbling secondary mirror to perform focusing, dithering (for near-infrared observations) and fast chopping (for mid-infrared observations). A plane tertiary mirror can alternatively feed the two Nasmyth foci. One of the Nasmyth focal stations will be equipped with AMICA (Antarctic Multiband Infrared Camera), a NIR/MIR double armed camera operating in the near- and mid-infrared spectral regions (Dolci et al. 2010), the other focus is foreseen for the CAMISTIC bolometer (Minier et al. 2007). First observations are expected for 2013.

- COCHISE is a Cassegrain $2.6 \mathrm{~m}$ millimetric telescope, with a wobbling secondary mirror and a field of view of few arc-minutes (Sabbatini et al. 2011). This telescope was installed in 2007 as a pathfinder for future Antarctic millimetric telescopes.

- QUBIC (formerly BRAIN) is a ground-based project of observational cosmology dedicated to measuring the Cosmic Microwave Background (CMB) polarization anisotropies (Piatt et al. 2012). QUBIC (Q\&U Bolometric Interferometer for Cosmology) is an international collaboration involving universities and laboratories in France, Italy, the U.K. and the U.S.A. The QUBIC instrument is based on bolometric interferometry, an innovative technology that is a promising alternative to direct imaging. The first module of the final instrument should be installed at Concordia in 2014.

- The ASTEP (Antarctica Search for Transiting Exo-Planet) program is dedicated to exoplanet transit search (Fig. 4). A pathfinder instrument called ASTEP South, a $10 \mathrm{~cm}$ refractor telescope, was installed in 2008 in order to evaluate the photometric capacities of the site (Crouzet et al. 2010) and is in operation since its installation. The main instrument, ASTEP 400, was then built in order to achieve the major objective of exoplanet detection.

ASTEP 400 is an optical $40 \mathrm{~cm}$ telescope with a field of view of $1^{\circ} \times 1^{\circ}$ (Daban et al. 2010). The achieved photometric sensitivity is about 1 mmag for the brightest stars of the field. The optical design of the instrument guarantees high homogeneity of the PSF sizes in the field of view. The use of carbon fibers in the telescope structure guarantees high stability. The focal optics and the detectors are enclosed in a thermally regulated box which withstands extremely low temperatures. The telescope designed to run at $-80^{\circ} \mathrm{C}$ was set up at Concordia during the Southern summer 2009-2010. It began its nightly observations in March 2010.

\section{References}

Agabi, A., Aristidi, E., Azouit, M., Fossat, E., Martin, F., Sadibekova, T., Vernin, J., \& Ziad, A., 2006, PASP, 118, 344

Aristidi, E., Agabi, A., Vernin, J., Azouit, M., Martin, F., Ziad, A., \& Fossat, E., 2003 A\&̊A, 406,19

Aristidi, E., Agabi, K., Azouit, M., Fossat, E., Vernin, J., Travouillon, T., Lawrence, J. S., Meyer, C., Storey, J. W. V., Halter, B., Roth, W. L., \& Waldern V., 2005a A\& $A, 430,739$ 
Aristidi, E., Agabi, A., Fossat, E., Azouit, M., Martin, F., Sadibekova, T., Travouillon, T., Vernin, J., \& Ziad, A., 2005b A $8 A$ A, 444, 651

Aristidi, E., Fossat, E., Agabi, A., Mékarnia, D., Jeanneaux, F., Bondoux, E., Challita, Z., Ziad, A., Vernin, J., \& Trinquet, H., 2009 A\&A, 499, 955

Crouzet, N., Guillot, T., Agabi, A., Rivet, J.-P., Bondoux, E., Challita, Z., Fantei-Caujolle, Y., Fressin, F., Mékarnia, D., Schmider, F.-X, et al., 2010 A\&A, 511,36

Daban, J.-B., Gouvret, C., Guillot, T., Agabi, A., Crouzet, N., Rivet, J.-P., Mékarnia, D., Abe, L., Bondoux, E., Fante-Caujolle, Y., et al., 2010 Proc. SPIE, 7733, 151

Dolci, M., et al. 2010 SPIE Proc., 7735, 121

Dempsey, J. T., Storey, J. W. V., \& Phillips, A., 2005, PASA, 22, 91

Fossat, E., Aristidi, E., Agabi, A., Bondoux, E., Challita, Z., Jeanneaux, F., \& Mékarnia, D., $2010 A \mathscr{E} A, 517,69$

Hertzog, A. et al., 2010 Cosp., 38, 4057.

Kenyon, S. L., Lawrence, J. S., Ashley, M. C. B., Storey, J. W. V., Tokovinin, A., \& Fossat, E., 2006 PASP, 118, 924

Kenyon, S. L., Storey, J. W. V., 2006 PASP, 118, 489

Lawrence, J. S., Ashley, M. C. B., Tokovinin, A., \& Travouillon, T., 2004, Nature, 431, 278

Minier, V., Durand, G., Lagage, P.-O., \& Talvard, M., 2007 HiA,14, 709

Mosser, B. \& Aristidi, E., 2007 PASP, 119, 127

Piatt et al., 2012 Journal of Low Temperature Physics, 167, 872

Sabbatini, L., Cavaliere, F., DallOglio, G., Miriametro, A., \& Pizzo, L., Mancini D., Torrioli G., 2011 Experimental Astronomy, 31, 199

Tosti, G. et al., 2006 Proc. SPIE, 6267 